\section{Commentary: Do as I say... but only if you can do as I do}

\author{
Gaetano Paone, MD, MHSA
}

In this month's Journal, Davierwala and colleagues ${ }^{1}$ report their experience with 2667 patients who underwent minimally invasive direct coronary artery bypass (MIDCAB) surgery from 1996 to 2018. Representing 9\% of their total coronary bypass volume, the cohort was divided into 3 roughly equal consecutive time periods. Left internal thoracic artery (LITA) harvest was via the left anterior thoracotomy incision and bypassed the left anterior descending artery (LAD) in all patients. Overall, in-hospital mortality was $0.9 \%$ and remained stable despite a progressive increase in associated patient risk factors and logistic European System for Cardiac Operative Risk Evaluation (ie, EuroSCORE) I over time.

The authors report numerous referrals from outside cardiologists, describe various LAD pathologies favoring MID$\mathrm{CAB}$ over percutaneous coronary intervention (PCI), and suggest that many others "... genuinely believe in the efficacy of the LITA graft to the LAD...compared with PCI." However, essentially one half of the cases were performed during the earliest period, with a lesser median case volume of 84 cases/y over the most recent 15 years. Despite ascribing this decrease to the introduction and growing use of drug-eluting stents, no comparative PCI volume data are available for any corresponding time period, and the extent to which decision-making involves a heart-team approach is unclear.

In the most recent period of 2011 to $2018,39.3 \%$ of patients had single-vessel disease and $27.4 \%$ had 3-vessel

\footnotetext{
From the Division of Cardiothoracic Surgery, Structural Heart and Valve Center, Emory University, School of Medicine, Atlanta, Ga.

Disclosures: The author reported no conflicts of interest.

The Journal policy requires editors and reviewers to disclose conflicts of interest and to decline handling or reviewing manuscripts for which they may have a conflict of interest. The editors and reviewers of this article have no conflicts of interest.

Received for publication Jan 22, 2021; revisions received Jan 22, 2021; accepted for publication Jan 25, 2021; available ahead of print Jan 30, 2021.

Address for reprints: Gaetano Paone, MD, MHSA, Division of Cardiothoracic Surgery, Structural Heart and Valve Center, Emory University Midtown Hospital, 550 Peachtree St, NE, Davis-Fischer Bldg, 4th floor, Atlanta, GA 30308 (E-mail: gaetano.paone@emory.edu).

J Thorac Cardiovasc Surg 2023;165:128-9

$0022-5223 / \$ 36.00$

Copyright (C) 2021 by The American Association for Thoracic Surgery

http://dx.doi.org/10.1016/j.jtcvs.2021.01.097
}

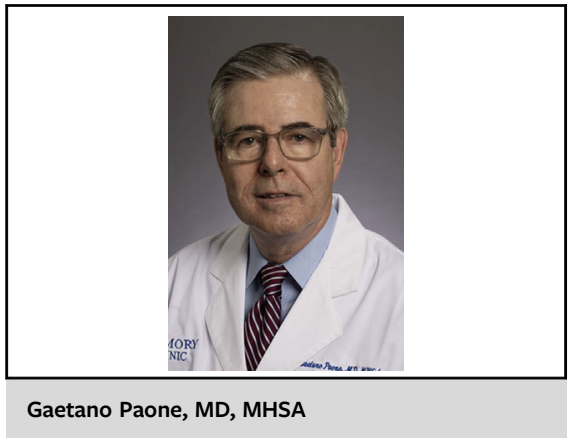

CENTRAL MESSAGE

This very experienced center reported excellent long-term outcomes after MIDCAB. The generalizability of these results remains uncertain.

disease. Given the statement that "...nearly every patient requiring an elective LITA-LAD bypass graft undergoes a MIDCAB procedure in our institute," it is uncertain how many patients underwent MIDCAB for true isolated LAD disease versus for various variants of multivessel disease, including after previous PCI or as part of a planned hybrid procedure. While previous trials comparing MIDCAB and PCI for isolated LAD disease have consistently demonstrated similar all-cause mortality and morbidity with increased rates of target-vessel reintervention after $\mathrm{PCI}^{2-4}$ the lack of a contemporary PCI cohort limits the ability to extrapolate any such comparison from these data.

Nonetheless, the authors should be congratulated for a long-standing commitment to the MIDCAB procedure and their outstanding results in this "largest" and "longest" single-center experience. The authors' conclusion that "MIDCAB can be safely performed with very good early and long-term outcomes" seems reasonable. However, by reporting that improvement in the "cumulative observed/expected ratio" for 30-day mortality began after "approximately 1000 procedures" and expressing concern that as a training center their results may potentially suffer by inclusion of "learning curve" outcomes, they seemingly add their own caveat regarding the technical challenges of MIDCAB and its generalizability to the everyday cardiac surgeon. ${ }^{5,6}$

While clearly providing a less-invasive approach for some, the role of MIDCAB in coronary revascularization awaits further clarification, both for the patient with isolated LAD disease, or as part of a hybrid procedure for those with 
multivessel disease. Recent discussion largely focused on increased use of off-pump and complex, multiarterial grafting has some proposing a potential benefit and need for "coronary revascularization specialists." ${ }^{7,8}$ So too, perhaps with MIDCAB, an admittedly undefined level of passion, experience, and technical proficiency is needed to maximize its potential.

\section{References}

1. Davierwala PM, Verevkin A, Bergien L, von Aspern K, Deo AV, Misfeld M, et al. Twenty-year outcomes of minimally invasive direct coronary artery bypass surgery: the Leipzig experience. J Thorac Cardiovasc Surg. 2023;165:115-27.e4.

2. Blazek S, Rossbach C, Borger MA, Fuernau G, Desch S, Eitel I, et al. Comparison of sirolimus-eluting stenting with minimally invasive bypass surgery for stenosis of the left anterior descending coronary artery: 7-year follow-up of a randomized trial. J Am Coll Cardiol Intverv. 2015;8:30-8.
3. Patel NC, Hemli JM, Seetharam K, Singh VP, Scheinerman SJ, Pirelli L, et al Minimally invasive coronary bypass versus percutaneous coronary intervention for isolated complex stenosis of the left anterior descending coronary artery. J Thorac Cardiovasc Surg. May 29, 2020 [Epub ahead of print].

4. Hannan EL, Zhong Y, Walford G, Holmes DR Jr, Venditti FJ, Berger PB, et al. Coronary artery bypass graft surgery versus drug-eluting stents for patients with isolated proximal left anterior descending disease. J Am Coll Cardiol. 2014;64: 2717-26.

5. LaPar DJ, Mery CM, Kozower BD, Kern JA, Kron IL, Stukenborg GJ, et al. The effect of surgeon volume on mortality for off-pump coronary artery bypass grafting. J Thorac Cardiovasc Surg. 2012;143:854-63.

6. Holzhey DM, Jacobs S, Walther T, Mochalski M, Mohr FW, Falk V. Cumulative sum failure analysis for eight surgeons performing minimally invasive direct coronary artery bypass. J Thorac Cardiovasc Surg. 2007;134:663-9.

7. Mack M, Taggart D. Coronary revascularization should be a subspecialty focus in cardiac surgery. J Thorac Cardiovasc Surg. 2019;157:945-7.

8. Puskas JD, Gaudino M, Taggart DP. Experience is crucial in off-pump coronary artery bypass grafting. Circulation. 2019;139:1872-5.
See Article page 115 .

\section{Commentary: Sternotomy for every cardiac surgery patient ain't the future, so let's get going}

\author{
Marc Ruel, MD, MPH, FRCSC, FAHA, FCCS
}

In this issue of the Journal, Davierwala and colleagues ${ }^{1}$ present their experience of 2667 patients who underwent minimally invasive direct coronary artery bypass grafts (MIDCABs) at the Leipzig Heart Center between 1996 and 2018 , which amounted to $9 \%$ of coronary artery bypass graft $(\mathrm{CABG})$ operations performed during that time. The number of MIDCABs decreased to about one-half the initial frequency during the last two-thirds of the study period,

\footnotetext{
From the University of Ottawa Heart Institute, University of Ottawa, Ottawa, Ontario, Canada.

Dr Ruel is a minimally invasive coronary artery bypass graft proctor and Principal Investigator of the MIST (Minimally Invasive coronary surgery compared to STernotomy coronary artery bypass grafting) trial (both with support from Medtronic, Inc).

The Journal policy requires editors and reviewers to disclose conflicts of interest and to decline handling or reviewing manuscripts for which they may have a conflict of interest. The editors and reviewers of this article have no conflicts of interest.

Received for publication Jan 24, 2021; revisions received Jan 24, 2021; accepted for publication Jan 25, 2021; available ahead of print Jan 30, 2021.

Address for reprints: Marc Ruel, MD, MPH, FRCSC, FAHA, FCCS, Division of Cardiac Surgery, University of Ottawa Heart Institute, 40 Ruskin St, Suite 3402,

Ottawa, Ontario, Canada (E-mail: mruel@ottawaheart.ca).

J Thorac Cardiovasc Surg 2023;165:129-31

$0022-5223 / \$ 36.00$

Copyright (c) 2021 by The American Association for Thoracic Surgery

http://dx.doi.org/10.1016/j.jtcvs.2021.01.096
}

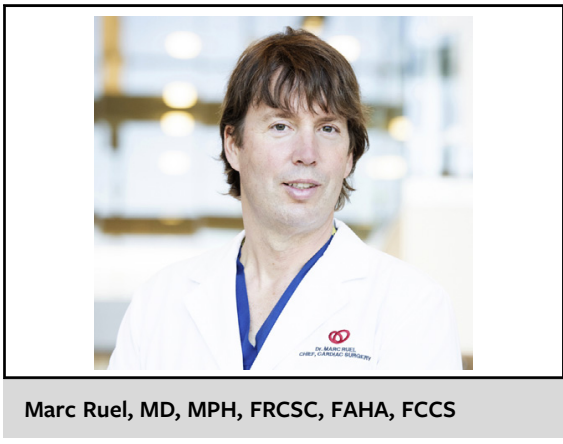

CENTRAL MESSAGE

Compelling surgical experiences

such as the one reported here by

Davierwala et al. have a key role in

telling the world about nonster-

notomy CABG and helping our

community better embrace it.

possibly as a result of more multivessel sternotomy off-pump coronary artery bypass and minimally invasive (MICS) CABGs being performed. ${ }^{2}$

In the Leipzig cohort, mean age was $64.5 \pm 10.9$ years, and $74 \%$ of patients were male. Notably, $55 \%$ of patients had single-vessel coronary artery disease, implying that hybrid or incomplete coronary revascularization may have occurred in a sizable proportion of patients. Cardiopulmonary bypass was used in $2 \%$ of patients and conversion to sternotomy occurred in $1 \%$. Perioperative mortality 